\title{
ARTICLE
}

\section{Food and health}

\section{Knowledge and behaviors regarding salt intake in Mozambique}

\author{
Neusa Jessen ${ }^{1,2} \cdot$ Artur Santos $^{3} \cdot$ Albertino Damasceno $^{1,2,4} \cdot$ Carla Silva-Matos $^{5} \cdot$ Milton Severo $^{2} \cdot$ Patrícia Padrão $^{2,6}$. \\ Nuno Lunet ${ }^{2,4}$
}

Received: 14 July 2017 / Revised: 20 January 2018 / Accepted: 5 February 2018

(c) Macmillan Publishers Limited, part of Springer Nature 2018

\begin{abstract}
Background/objectives Health education and regulatory measures may contribute to lower population salt intake. Therefore, we aimed to describe knowledge and behaviors related to salt intake in Mozambique.

Subjects/methods A cross-sectional evaluation of a representative sample of the population aged 15-64 years $(n=3116)$ was conducted in 2014/2015, following the Stepwise Approach to Chronic Disease Risk Factor Surveillance, including a 12question module for evaluation of dietary salt.

Results Three dimensions were identified in the questionnaire, named "self-reported salt intake", "knowledge of health effects of salt intake", and "behaviors for control of salt intake". A total of 7.4\% of the participants perceived that they consumed too much/far too much salt and $25.9 \%$ reported adding salt/salty seasoning often/always to prepared foods. The proportion considering that it was not important to decrease the salt contents of their diet was $8 \%$, and $16.9 \%$ were not aware that high salt intake could be deleterious for health. Prevalences of lack of behaviors for reducing salt intake ranged from $74.9 \%$ for not limiting consumption of processed foods, to $95 \%$ for not buying low salt alternatives. There were few differences according to socio-demographic variables, but awareness of hypertension was, in general, associated with better knowledge and less frequent behaviors likely to contribute to a high salt intake.

Conclusions Most Mozambicans were aware that high salt intake can cause health problems, but the self-reported salt intake and behaviors for its control show an ample margin for improvement. This study provides evidence to guide population level salt-reducing policies.
\end{abstract}

Neusa Jessen

neusa.jessen@gmail.com

1 Faculdade de Medicina, Universidade Eduardo Mondlane, Av. Salvador Allende 702, Maputo, Mozambique

2 EPIUnit-Instituto de Saúde Pública, Universidade do Porto, Rua das Taipas, no. 135, 4050-600 Porto, Portugal

3 Faculdade de Ciências de Saúde, Universidade Lurio, Bairro de Marrere, Rua número 4250, Km2.3, Nampula, Mozambique

4 Departamento de Ciências da Saúde Pública e Forenses e Educação Médica, Faculdade de Medicina da Universidade do Porto, Alameda Prof. Hernâni Monteiro, 4200-319 Porto, Portugal

5 Unidade de Gestão do Fundo Global—Direção de Planificação e Cooperação, Ministério da Saúde de Moçambique, Av. Eduardo Mondlane, 1008 Maputo, Mozambique

6 Faculdade de Ciências da Nutrição e Alimentação da Universidade do Porto, Rua Dr. Roberto Frias, 4200-465 Porto, Portugal

\section{Introduction}

Salt is consumed in excess all around the world $[1,2]$ and has been associated to important public health problems, especially cardiovascular diseases (CVD). Sodium intake may lead to the latter by increasing blood pressure, or by influencing directly the risk of stroke and coronary heart disease $[1,3,4]$. In addition, high consumption of salt has been related to gastric cancer [5, 6], osteoporosis, and renal stones $[7,8]$.

Although sodium intake varies widely across countries, a global mean of almost $4 \mathrm{~g} /$ day was estimated [2], which is the double of the World Health Organization (WHO) recommended limit for adults, which is $<2 \mathrm{~g} /$ day $(5 \mathrm{~g} /$ day of salt) [9]. Contrarily to the observed for other cardiovascular dietary risk factors, sodium intake was not shown to be associated with the national income [2]. In Sub-Saharan Africa (SSA), although high quality data are lacking, a review of 34 studies conducted in 13 countries, also found a consumption of sodium above the WHO recommendations in most settings, especially in urban areas [10]. 
Specifically in Mozambique, although direct evidence of high sodium intake is scarce, a recent study based on 24-h urine samples of 100 Maputo dwellers showed mean urinary sodium excretion compatible with a daily intake twice the recommended by the WHO [11]. This is in line with the high prevalence of hypertension in Mozambique (two out of every five adults) [12].

Understanding how people perceive their levels of exposure and corresponding health risks may support the development and implementation of sodium intake control measures, either at a population level, or targeting high-risk groups. The present study aimed to describe the knowledge and behaviors related to dietary salt intake in the Mozambican population, overall and according to sociodemographic variables and awareness of hypertension.

\section{Methods}

The present report is based on a cross-sectional study of a representative sample of the Mozambican population aged 15-64 years, conducted between December 2014 and February 2015.

\section{Selection of participants}

The sample was designed based on data from the 2007 census [13], to be representative at the national level and provincial levels, and according to the residence in urban or rural areas; the homeless and people living in collective residential institutions (e.g., hotels, hospitals, military facilities), whom are estimated to correspond to $\sim 1.6 \%$ of the population, were not eligible. Participants were selected through a complex sampling design including clustering at the level of geographical units and households, and stratification according to province, urban/rural areas and socioeconomic strata; the latter were considered only in cities with more than 20,000 households. It comprised the random selection of 120 geographical clusters (100-150 households in the urban areas and 80-100 households in the rural areas) among which all of the households were listed and 24 randomly selected and visited. Within each selected household, all dwellers aged 15-64 years were listed and a maximum of two were selected, one aged 15-44 years and one aged 45-64 years, whenever available; when there was more than one household member in each of these agegroups, only one per group was randomly selected, using a Kish selection grid.

A total of 3277 subjects were invited, and 3119 agreed to participate (participation proportion: $95.2 \%$ ).

Sampling weights were computed, taking into account the number of subjects evaluated in each stratum in relation to the number of participants expected per stratum according to the population projections for the same period.

\section{Evaluation of participants}

Subjects were evaluated using the standardized methods, according to WHO STEPwise approach to chronic disease risk factor surveillance (STEPS) [14]. Face-to-face interviews were conducted by trained interviewers, using a Portuguese version of the WHO STEPS instrument for noncommunicable disease risk factors surveillance (Core and Expanded version 3.0), including the module for evaluation of dietary salt [15]; the questions included in the latter module are presented in Table 1.

Blood pressure was measured on a single occasion by non-physician trained interviewers using a semiautomatic sphygmomanometer (Bosch \& Sohn Medicus UNO) with an universal cuff of $22-42 \mathrm{~cm}$. After a 5-min rest, blood pressure was measured three times, with a three minutes interval between each two measurements. For analysis, we used the mean of the two first measurements if they differed by $10 \mathrm{mmHg}$ or less, for systolic and diastolic blood pressure, or the mean of the last two otherwise [12, 14].

Arterial hypertension was defined as systolic blood pressure $\geq 140 \mathrm{mmHg}$ and/or diastolic blood pressure $\geq 90 \mathrm{mmHg}$ and/or antihypertensive drug therapy in the previous two weeks. Hypertensive subjects were considered to be aware of hypertension when having been told by a health professional, in the previous 12 months, that they had hypertension or high blood pressure, or when reporting a pharmacological treatment for hypertension.

\section{Statistics}

A total of 3116 subjects for whom information on at least one of variables of the dietary salt module was available were considered for data analysis.

To identify the dimensionality of the variables that make the dietary salt module of the STEPS questionnaire we used principal components analysis with varimax rotation. According to the Kaiser's criterion to define the number of questionnaire components, we retained those with eigenvalues $>1$. We considered that items belonged to a specific component when the factor loadings were higher than 0.4 . The reliability of the dimensions was measured using the Cronbach's alpha; as the number of items in each dimension was smaller than 15 , values above 0.5 were interpreted as indicating good reliability [16]. The statistical package $\mathrm{R}$ 3.3.1 was used for data analysis [17].

We computed prevalences for each of the variables of the dietary salt questionnaire, and added up the ratings of each item belonging to the same component to obtain componentspecific scores. We computed adjusted prevalence ratios (PR), 


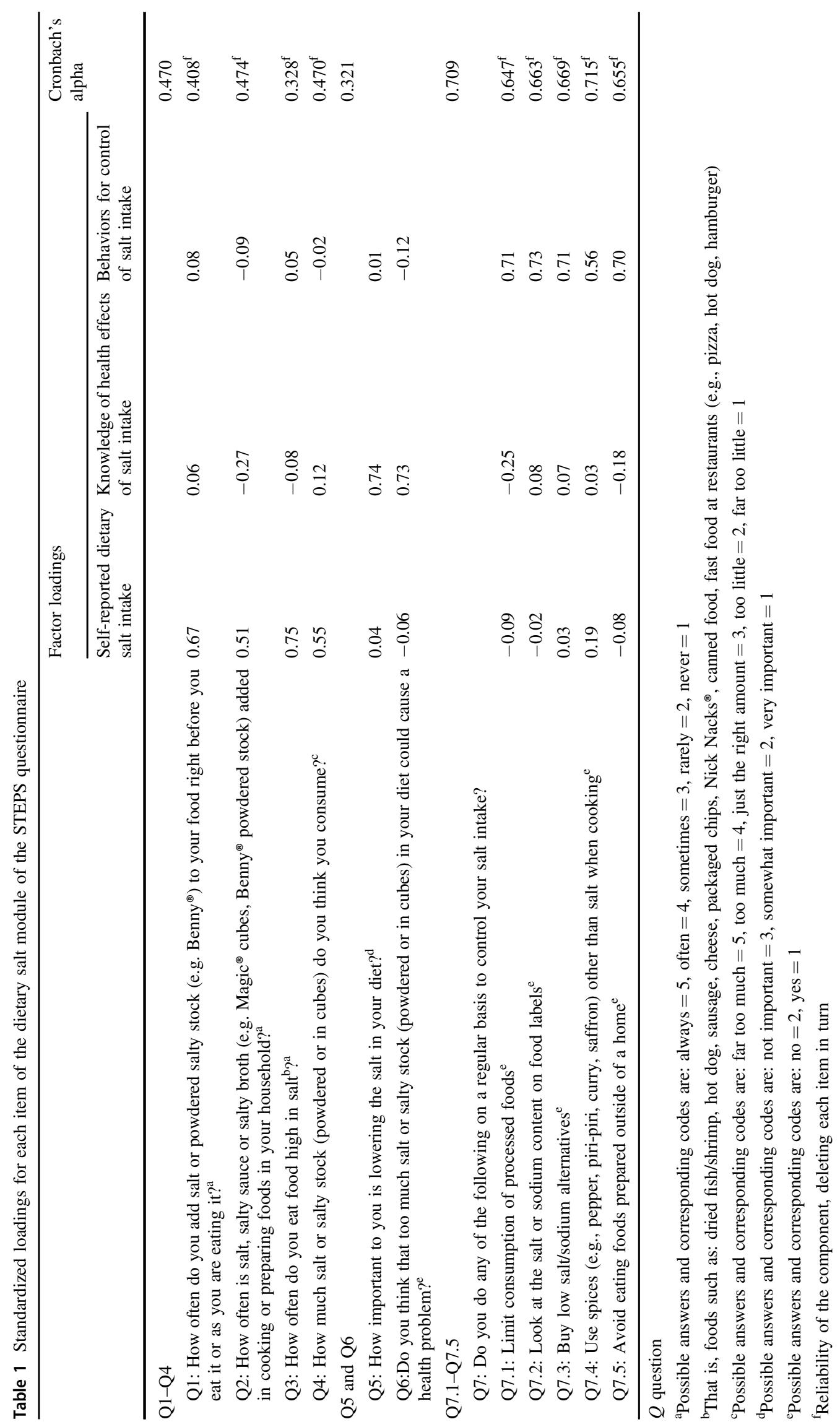


using Poisson regression, and adjusted regression coefficients, using linear regression, respectively, according to sociodemographic characteristics and hypertensive status. The analyses were conducted considering the sampling weights and adjusting for stratification by province and clustering at the primary sampling unit level, using STATA $^{\circledR}$, version 11.2 (StataCorp, College Station, TX, USA).

\section{Ethics}

This study was conducted according to the guidelines laid down in the Declaration of Helsinki and all procedures involving human subjects were approved by the National Bioethics Committee for Health. Written informed consent was obtained from all participants.

\section{Results}

\section{Characteristics of participants}

Just over $60 \%$ of the population under study was rural, almost 30\% was aged 15-24 years and approximately onefourth had between 45 and 64 years. One quarter had secondary or higher education and another quarter had no formal education. Around 31\% had high blood pressure and $5 \%$ were hypertensive subjects aware of their status.

\section{Dimensions of the dietary salt questionnaire}

Three components were identified in the dietary salt questionnaire, explaining $48 \%$ of the variance (Table 1). The four questions related with the consumption of salt or salty foods had high factor loadings for the same component, which was named "self-reported dietary salt intake"; the minimum and maximum possible values for the score were 4 and 20 , respectively, and the mean score (range) was 11.8 [4-20]. A component with high factor loadings for the two questions regarding the participants' knowledge regarding the potential health implications of dietary salt was named "knowledge of health effects of salt intake"; the minimum and maximum possible values for the score were 2 and 5, respectively, and the mean score (range) was 2.8 [2-5]. The five questions referring to the adoption of different strategies to reduce salt intake had high factor loadings for the same component, which was named "behaviors for control of salt intake"; the minimum and maximum possible values were 5 and 10 , respectively and the mean score (range) was 9.3 [5-10].

\section{Self-reported dietary salt intake}

A total of $7.4 \%$ of the participants perceived that they consumed too much/far too much salt whereas $16.5 \%$ referred that they consumed foods high in salt often/ always. The percentage reporting the addition of salt or salty seasoning often/always to prepared foods or during preparation was $25.9 \%$ and $61.4 \%$, respectively. As shown in Table 2, there were no significant differences according to place of residence or sex. Compared to participants aged 15-24 years, those who were older reported lower intake of foods high in salt (25-44 years: $\mathrm{PR}=0.75,95 \%$ CI: $0.61,0.93 ; 45-64$ years: $\mathrm{PR}=0.70$, $95 \%$ CI: $0.55,0.89$ ). Higher levels of education ( $>7$ vs. 0 schooling years) were associated with more frequent use of salt when preparing foods ( $\mathrm{PR}=1.36,95 \% \mathrm{CI}$ : 1.18 , 1.56) and perception of higher salt intake $(\mathrm{PR}=2.01$, $95 \%$ CI: $1.28,3.16)$. In comparison with non-hypertensive subjects, those aware of their hypertensive status were less likely to add salt to prepared foods ( $\mathrm{PR}=0.60,95 \% \mathrm{CI}$ : $0.43,0.85)$ or to eat food high in salt $(\mathrm{PR}=0.65,95 \% \mathrm{CI}$ : $0.43,1.00)$. There were no significant differences when hypertensives not aware of their condition were compared with the non-hypertensive.

When considering all the variables that reflect selfreported salt intake (Table 3), scores were significantly lower among older participants than in those aged 15-24 years (25-44 years: $\beta=-0.52,95 \%$ CI: $-0.85,-0.18$; 45-64 years: $\beta=-0.83,95 \%$ CI: $-1.25,-0.41)$ and among hypertensive subjects aware of their condition than in those not hypertensive $(\beta=-0.55,95 \% \mathrm{CI}:-1.03$, $-0.06)$.

\section{Knowledge regarding health effects of salt intake}

The proportion of participants that considered that it was not important to decrease the salt contents of their diet was $8.0 \%$, and $16.9 \%$ of the participants were not aware that too much salt in diet could have deleterious effects on health. There were no significant differences according to place of residence or age of the participants (Table 4). Not recognizing the importance of lowering dietary salt intake was more frequent among men ( $\mathrm{PR}=1.95,95 \% \mathrm{CI}: 1.39,2.73)$ and not considering that high salt intake could cause health problems was less frequent among the more educated than in participants with no formal education (1-7 schooling years: $\mathrm{PR}=0.59,95 \% \mathrm{CI}: 0.46,0.74 ;>7$ schooling years: $\mathrm{PR}=0.38,95 \% \mathrm{CI}: 0.26,0.56$ ), and among hypertensives aware of their condition than in non-hypertensive subjects $(\mathrm{PR}=0.29,95 \% \mathrm{CI}: 0.15,0.55)$. The latter associations were also observed for the score summarizing the knowledge of health effects of salt intake (Table 3).

\section{Behaviors for control of salt intake}

As shown in Table 5, most participants did not report behaviors that are expected to contribute for reduction of 
Table 2 Behaviors related to salt intake in Mozambique, in 2014/2015, according to place of residence, sex, age, education, and hypertensive status

\begin{tabular}{|c|c|c|c|c|c|c|c|c|c|c|c|c|}
\hline & \multicolumn{3}{|c|}{$\begin{array}{l}\text { Adds salt/salty seasoning to } \\
\text { prepared food (often or } \\
\text { always) }^{\mathrm{a}}\end{array}$} & \multicolumn{3}{|c|}{$\begin{array}{l}\text { Adds salt/salty seasoning } \\
\text { preparing foods (often or } \\
\text { always) }\end{array}$} & \multicolumn{3}{|c|}{$\begin{array}{l}\text { Eats food high in salt } \\
\text { (often or always) }^{c}\end{array}$} & \multicolumn{3}{|c|}{$\begin{array}{l}\text { Perceived salt intake (too } \\
\text { much or far too much) }\end{array}$} \\
\hline & $\%$ & PR & $95 \% \mathrm{CI}$ & $\%$ & PR & $95 \%$ CI & $\%$ & PR & $95 \%$ CI & $\%$ & PR & $95 \% \mathrm{CI}$ \\
\hline \multicolumn{13}{|l|}{ Place of residence } \\
\hline Rural & 25 & 1 & {$[$ Ref $]$} & 58.2 & 1 & {$[\mathrm{Ref}]$} & 15.0 & 1 & {$[\mathrm{Ref}]$} & 7.5 & 1 & {$[\operatorname{Ref}]$} \\
\hline Urban & 27.3 & 1.13 & {$[0.80,1.59]$} & 66.3 & 1.03 & {$[0.85,1.26]$} & 18.8 & 1.21 & {$[0.85,1.72]$} & 7.3 & 0.89 & {$[0.57,1.39]$} \\
\hline \multicolumn{13}{|l|}{ Sex } \\
\hline Female & 24.9 & 1 & [Ref] & 62.9 & 1 & [Ref] & 15.6 & 1 & [Ref] & 7.3 & 1 & [Ref] \\
\hline Male & 27.2 & 0.99 & {$[0.87,1.14]$} & 59.2 & 0.92 & {$[0.86,0.98]$} & 17.8 & 1.14 & {$[0.90,1.44]$} & 7.6 & 0.94 & {$[0.65,1.35]$} \\
\hline \multicolumn{13}{|l|}{ Age (years) } \\
\hline $15-24$ & 29.5 & 1 & {$[\mathrm{Ref}]$} & 67.1 & 1 & {$[\mathrm{Ref}]$} & 20.5 & 1 & [Ref] & 9.1 & 1 & [Ref] \\
\hline $25-44$ & 23.8 & 0.81 & {$[0.67,0.99]$} & 59.8 & 0.97 & {$[0.89,1.06]$} & 15.1 & 0.75 & {$[0.61,0.93]$} & 7.3 & 1.02 & {$[0.74,1.41]$} \\
\hline $45-64$ & 25.4 & 0.91 & {$[0.76,1.09]$} & 57.8 & 0.95 & {$[0.85,1.07]$} & 14.4 & 0.70 & {$[0.55,0.89]$} & 5.7 & 0.85 & {$[0.54,1.33]$} \\
\hline \multicolumn{13}{|l|}{ Education $^{\mathrm{e}}$} \\
\hline 0 & 22.1 & 1 & {$[\mathrm{Ref}]$} & 54.2 & 1 & {$[\mathrm{Ref}]$} & 14.7 & 1 & {$[\mathrm{Ref}]$} & 4.9 & 1 & [Ref] \\
\hline $1-7$ & 27.8 & 1.24 & {$[0.95,1.62]$} & 59.1 & 1.11 & {$[0.98,1.25]$} & 16.4 & 1.04 & {$[0.79,1.37]$} & 7.5 & 1.48 & {$[0.94,2,34]$} \\
\hline$>7$ & 26.5 & 1.08 & {$[0.78,1.50]$} & 73.8 & 1.36 & {$[1.18,1.56]$} & 18.9 & 1.08 & {$[0.76,1.54]$} & 9.9 & 2.01 & {$[1.28,3.16]$} \\
\hline \multicolumn{13}{|l|}{ Hypertension } \\
\hline Not hypertensive & 25.3 & 1 & [Ref] & 62.4 & 1 & [Ref] & 16.6 & 1 & {$[\operatorname{Ref}]$} & 7.8 & 1 & [Ref] \\
\hline Hypertensive not aware & 27.3 & 1.13 & {$[0.95,1.34]$} & 56.2 & 0.96 & {$[0.86,1.07]$} & 17.6 & 1.19 & {$[0.90,1.58]$} & 6.8 & 0.99 & {$[0.65,1.51]$} \\
\hline Hypertensive aware & 15.6 & 0.60 & {$[0.43,0.85]$} & 68.3 & 1.08 & {$[0.94,1.24]$} & 9.8 & 0.65 & {$[0.43,1.00]$} & 4.3 & 0.60 & {$[0.32,1.13]$} \\
\hline
\end{tabular}

$C I$ confidence interval, $P R$ prevalence ratio

${ }^{\text {a }}$ How often do you add salt or powdered salty stock (e.g., Benny ${ }^{\circledR}$ ) to your food right before you eat it or as you are eating it?

${ }^{b}$ How often is salt, salty sauce or salty broth (e.g., Magic ${ }^{\circledR}$ cubes, Benny ${ }^{\circledR}$ powdered stock) added in cooking or preparing foods in your household?

${ }^{\mathrm{c}}$ How often do you eat food high in salt?

${ }^{\mathrm{d}}$ How much salt or salty stock (powdered or in cubes) do you think you consume?

${ }^{\mathrm{e}}$ Complete years

salt intake; prevalences ranged from $74.9 \%$ for not limiting the consumption of processed foods, to $95.0 \%$ for not buying low salt alternatives. Overall, unhealthier behaviors towards the control of salt intake were less frequent among urban dwellers $(\beta=-0.19,95 \%$ CI: $-0.37,-0.01)$, the older $(\beta=-0.17,95 \% \mathrm{CI}:-0.31,-0.02)$ and the more educated participants $(\beta=-0.34,95 \%$ CI: $-0.47,-0.20)$, whereas men had worse scores $(\beta=0.12,95 \%$ CI: 0.03 , 0.22) (Table 3).

\section{Discussion}

The present study was the first to assess knowledge and behaviors of the Mozambican population regarding dietary salt intake using the STEPS questionnaire. This instrument was shown to evaluate essentially perceived salt intake, knowledge regarding its health effects, and behaviors to limit the exposure to dietary salt.
Most participants were aware that consuming too much salt can cause health problems, and even so, there was a high proportion of self-reported high salt intake and a low proportion of participants reporting the adoption of behaviors to control its consumption. Similar results were found in other countries [18-21], either when salt consumption was evaluated by self-report $[19,20]$ or by $24 \mathrm{~h}$ urinary excretion $[18,21]$.

Very few studies assessed knowledge and practices regarding dietary salt in African populations. In a literature review including 22 studies [22], three evaluated populations from developing countries. It was shown that, $80 \%$ or more of the participants knew that reducing salt consumption is beneficial for health. This is in accordance with our findings and also with other studies [18, 22, 23]. Nevertheless, knowledge of the population regarding salt, sodium and the related health risks, has been shown to be usually very limited and equivocal. Participants are frequently unable to tell the recommended daily salt intake [20, 24- 
Table 3 Self-reported salt intake, perception of health effects of salt intake, and behaviors for control of salt intake in Mozambique, in 2014/2015, according to place of residence, sex, age, education, and hypertensive status

\begin{tabular}{|c|c|c|c|c|c|c|c|c|c|}
\hline & \multicolumn{3}{|c|}{ Self-reported dietary salt intake } & \multicolumn{3}{|c|}{$\begin{array}{l}\text { Perception of health effects of salt } \\
\text { intake }\end{array}$} & \multicolumn{3}{|c|}{ Behaviors for control of salt intake } \\
\hline & Mean score & $\beta$ & $95 \% \mathrm{CI}$ & Mean score & $\beta$ & $95 \% \mathrm{CI}$ & Mean score & $\beta$ & $95 \% \mathrm{CI}$ \\
\hline \multicolumn{10}{|l|}{ Place of residence } \\
\hline Rural & 11.56 & {$[\mathrm{Ref}]$} & - & 2.88 & [Ref] & - & 9.37 & [Ref] & - \\
\hline Urban & 12.20 & 0.50 & {$[-0.15,1.02]$} & 2.74 & -0.07 & {$[-0.17,0.03]$} & 9.09 & -0.19 & {$[-0.37,-0.01]$} \\
\hline \multicolumn{10}{|l|}{ Sex } \\
\hline Female & 11.74 & {$[$ Ref $]$} & - & 2.81 & [Ref] & - & 9.22 & [Ref] & - \\
\hline Male & 11.96 & 1.85 & {$[-0.12,0.49]$} & 2.84 & 0.05 & {$[-0.02,0.12]$} & 9.32 & 0.12 & {$[0.03,0.22]$} \\
\hline \multicolumn{10}{|l|}{ Age (years) } \\
\hline $15-24$ & 12.40 & [Ref] & - & 2.81 & [Ref] & - & 9.28 & [Ref] & - \\
\hline $25-44$ & 11.72 & -0.52 & {$[-0.85,-0.18]$} & 2.84 & -0.01 & {$[-0.11,0.09]$} & 9.27 & -0.12 & {$[-0.24,0.01]$} \\
\hline $45-64$ & 11.40 & -0.83 & {$[-1.25,-0.41]$} & 2.82 & 0.01 & {$[-0.13,0.15]$} & 9.23 & -0.17 & {$[-0.31,-0.02]$} \\
\hline \multicolumn{10}{|l|}{ Education $^{\mathrm{a}}$} \\
\hline 0 & 11.43 & {$[\operatorname{Ref}]$} & - & 2.92 & {$[\mathrm{Ref}]$} & - & 9.35 & {$[\mathrm{Ref}]$} & - \\
\hline $1-7$ & 11.80 & 0.23 & {$[-0.21,0.67]$} & 2.82 & -0.11 & {$[-0.20,-0.03]$} & 9.35 & -0.05 & {$[-0.15,0.05]$} \\
\hline$>7$ & 12.33 & 0.42 & {$[-0.02,0.86]$} & 2.73 & -0.16 & {$[-0.28,-0.04]$} & 9.01 & -0.34 & {$[-0.47,-0.20]$} \\
\hline \multicolumn{10}{|l|}{ Hypertension } \\
\hline Not hypertensive & 11.88 & {$[\operatorname{Ref}]$} & - & 2.83 & [Ref] & - & 9.28 & [Ref] & - \\
\hline Hypertensive not aware & 11.75 & 0.15 & {$[-0.23,0.53]$} & 2.87 & -0.00 & {$[-0.11,0.11]$} & 9.32 & 0.04 & {$[-0.07,0.14]$} \\
\hline Hypertensive aware & 11.12 & -0.55 & {$[-1.03,-0.06]$} & 2.52 & -0.29 & {$[-0.41,-0.18]$} & 8.94 & -0.20 & {$[-0.42,0.02]$} \\
\hline
\end{tabular}

CI confidence interval

${ }^{\mathrm{a}}$ Complete years

26], the relation between salt and sodium [22, 24] and show wrong perception of their own high salt consumption [21, $23,25,27]$. The latter may contribute to the low proportion of participants who reported adopting practices known to reduce salt consumption observed in our study. Other reasons may be the desire of eating something palatable, which is considered a strong determinant for diet practices [28] and, in Mozambique, the rapid urbanization [29, 30], with crescent adverse food environment.

Disclosing the salt content of the products and promoting a proper interpretation of food labels are important measures for controlling salt intake [31]. However, reading labels was uncommonly reported in our study, such as in other studies performed in developing countries [19, 21], including in SSA [23, 24]. Although the Mozambican regulation for food labels [32] defines that the labels of packaged foods and beverages should be written in Portuguese and include, among other elements, the nutrient content, it does not define the specific items to be referred. On the basis of our experience in a previous survey [33], the sodium content is often not available.

We believe that some questions of the STEPS instrument (Table 1, questions codes: 7.1-7.3 and 7.5) for salt evaluation are not equally useful in all settings; in populations with low levels of education and limited access to health information along with low purchasing power, such as in Mozambique [13], it is unlikely that rural dwellers have the chance to eat out, buy packed foods or even possess sufficient knowledge to interpret food labels. In fact, in our study, higher education was associated with better perception of high salt intake, better knowledge of health effects of this practice and limitation of processed food consumption. In addition, rural dwellers reported worse knowledge and behaviors regarding salt consumption. In African countries, salt is used for preservation of food, especially in rural areas, and for making it tastier, while urban dwellers are more exposed to processed foods [34], explaining the exposure to salt in both settings.

In agreement with our results, studies performed worldwide show that, overall, women have higher knowledge and healthier behaviors regarding salt intake $[20,35,36]$, even among highly educated populations [26]. This observation may reflect a more frequent engagement in health promoting practices than men, due to a greater use of health services [37]. Also, as the consumption of salt is correlated with energy intake, and women tend to consume less energy than men, salt intake is expectedly lower among women [2]. Even so, evaluations of sodium intakes around the world, show small 
Table 4 Knowledge regarding health effects of salt intake in Mozambique, in 2014/2015, according to place of residence, sex, age, education, and hypertensive status

\begin{tabular}{|c|c|c|c|c|c|c|}
\hline & \multicolumn{3}{|c|}{$\begin{array}{l}\text { Is it important to } \\
\text { lower the salt in your } \\
\text { diet? (no) })^{\text {a }}\end{array}$} & \multicolumn{3}{|c|}{$\begin{array}{l}\text { Too much salt or salty } \\
\text { sauce in your diet } \\
\text { could cause a health } \\
\text { problem? (no) }{ }^{\text {b }}\end{array}$} \\
\hline & $\%$ & PR & $95 \% \mathrm{CI}$ & $\%$ & PR & $95 \% \mathrm{CI}$ \\
\hline \multicolumn{7}{|l|}{ Place of residence } \\
\hline Rural & 8.4 & 1 & [Ref] & 19.7 & 1 & [Ref] \\
\hline Urban & 7.4 & 0.97 & $\begin{array}{l}{[0.62} \\
1.51]\end{array}$ & 12.5 & 0.80 & $\begin{array}{l}{[0.55,} \\
1.17]\end{array}$ \\
\hline \multicolumn{7}{|l|}{ Sex } \\
\hline Female & 5.5 & 1 & [Ref] & 17.6 & 1 & [Ref] \\
\hline Male & 11.4 & 1.95 & $\begin{array}{l}{[1.39,} \\
2.73]\end{array}$ & 15.8 & 1.00 & $\begin{array}{l}{[0.81,} \\
1.23]\end{array}$ \\
\hline \multicolumn{7}{|l|}{ Age (years) } \\
\hline $15-24$ & 7.0 & 1 & {$[\mathrm{Ref}]$} & 15.3 & 1 & [Ref $]$ \\
\hline $25-44$ & 8.8 & 1.42 & $\begin{array}{l}{[0.92,} \\
2.19]\end{array}$ & 16.7 & 0.88 & $\begin{array}{l}{[0.68,} \\
1.14]\end{array}$ \\
\hline $45-64$ & 7.6 & 1.24 & $\begin{array}{l}{[0.68,} \\
2.25]\end{array}$ & 18.9 & 1.08 & $\begin{array}{l}{[0.81,} \\
1.45]\end{array}$ \\
\hline \multicolumn{7}{|l|}{ Education $^{\mathrm{c}}$} \\
\hline 0 & 5.9 & 1 & [Ref] & 26.4 & 1 & [Ref] \\
\hline $1-7$ & 8.4 & 1.27 & $\begin{array}{l}{[0.87,} \\
1.87]\end{array}$ & 15.5 & 0.59 & $\begin{array}{l}{[0.46,} \\
0.74]\end{array}$ \\
\hline$>7$ & 8.9 & 1.40 & $\begin{array}{l}{[0.78} \\
2.51]\end{array}$ & 9.1 & 0.38 & $\begin{array}{l}{[0.26} \\
0.56]\end{array}$ \\
\hline \multicolumn{7}{|l|}{ Hypertension } \\
\hline Not hypertensive & 8.4 & 1 & {$[\mathrm{Ref}]$} & 17.4 & 1 & [Ref] \\
\hline $\begin{array}{l}\text { Hypertensive not } \\
\text { aware }\end{array}$ & 8.1 & 0.90 & $\begin{array}{l}{[0.52,} \\
1.56]\end{array}$ & 18.3 & 0.90 & $\begin{array}{l}{[0.72,} \\
1.13]\end{array}$ \\
\hline Hypertensive aware & 4.0 & 0.51 & $\begin{array}{l}{[0.24,} \\
1.10]\end{array}$ & 5.0 & 0.29 & $\begin{array}{l}{[0.15,} \\
0.55]\end{array}$ \\
\hline
\end{tabular}

$C I$ confidence interval, $P R$ prevalence ratio

${ }^{a}$ How important to you is lowering the salt in your diet?

${ }^{b}$ Do you think that too much salt or salty stock (powdered or in cubes) in your diet could cause a health problem?

${ }^{\mathrm{c}}$ Complete years

differences between sexes [2], which is probably the result of exposure to similar environments and diet for men and women [19]. In the African context, women may represent an important target for population level salt-reduction campaigns, as they are usually responsible for food acquisition and preparation, having an important role in the salt consumption of the entire family $[38,39]$.

High sodium intake is related to raised blood pressure [40, 41] and lowering sodium consumption reduces blood pressure in hypertensive and nonhypertensive subjects [42, 43], more strongly in black people, who may have greater benefits from dietary salt reduction [41, 44, 45]. In accordance with the present investigation, a cross-sectional study conducted in China found healthier behaviors in hypertensives aware of their condition [36]. These findings are important to guide population level salt-reduction initiatives, suggesting that improving awareness of the population regarding their hypertensive status and the relation to high sodium diets may lead to better behaviors, and better control of hypertension. Simple, realistic and culturally driven ways of conveying clear and practical salt and hypertension messages, emphasizing the importance of dietary salt reduction, the recommended levels and how to do it with local solutions, should be developed and transmitted to the communities.

The WHO highly recommends [46] awareness raising, which has been shown a cost-effective [47] and essential step to change behaviors and reduce salt consumption at a population level [48], especially in developing countries, where addition of salt during food preparation or as seasoning on table were found to represent the main contributors to sodium intake [1, 48]. In Mozambique, a recent investigation [11] found that discretionary sodium was the main source of salt consumption, corresponding to just over $60 \%$ of the total dietary sodium intake. In order to improve salt control actions, and, to reach the higher educated groups of the population, other strategies should also be adopted, probably by involving the government and industry, targeting processed foods [27].

The major strength of this study is the fact that it was based in a representative sample of the Mozambican population, including ages 15-64 years. Also importantly, a standardized questionnaire was used, which can enable valid comparisons. The questionnaire proved to have a good internal consistency, allowing the construction of scores that may be used to summarize the information obtained with this standardized instrument for data collection. Nevertheless, some limitations should be discussed. First, the cross-sectional design, with simultaneous measurement of knowledge and practices, precludes causal inferences without an assumption that practices where driven by knowledge, which seems more likely, though we cannot exclude the hypothesis that individuals with better knowledge and practices regarding salt consumption were also more likely to have their blood pressure measured. Second, self-reported salt-lowering dietary behaviors are prone to social desirability bias. To reduce this possibility, the interviewers were trained to ask questions in a nonjudgmental way. Nevertheless, such a bias would have contributed for an overestimation of the proportion of participants adopting healthier behaviors and an underestimation of the proportions reporting frequent salt intake, and therefore the present study is likely to provide conservative estimates of inappropriate knowledge and behaviors. 


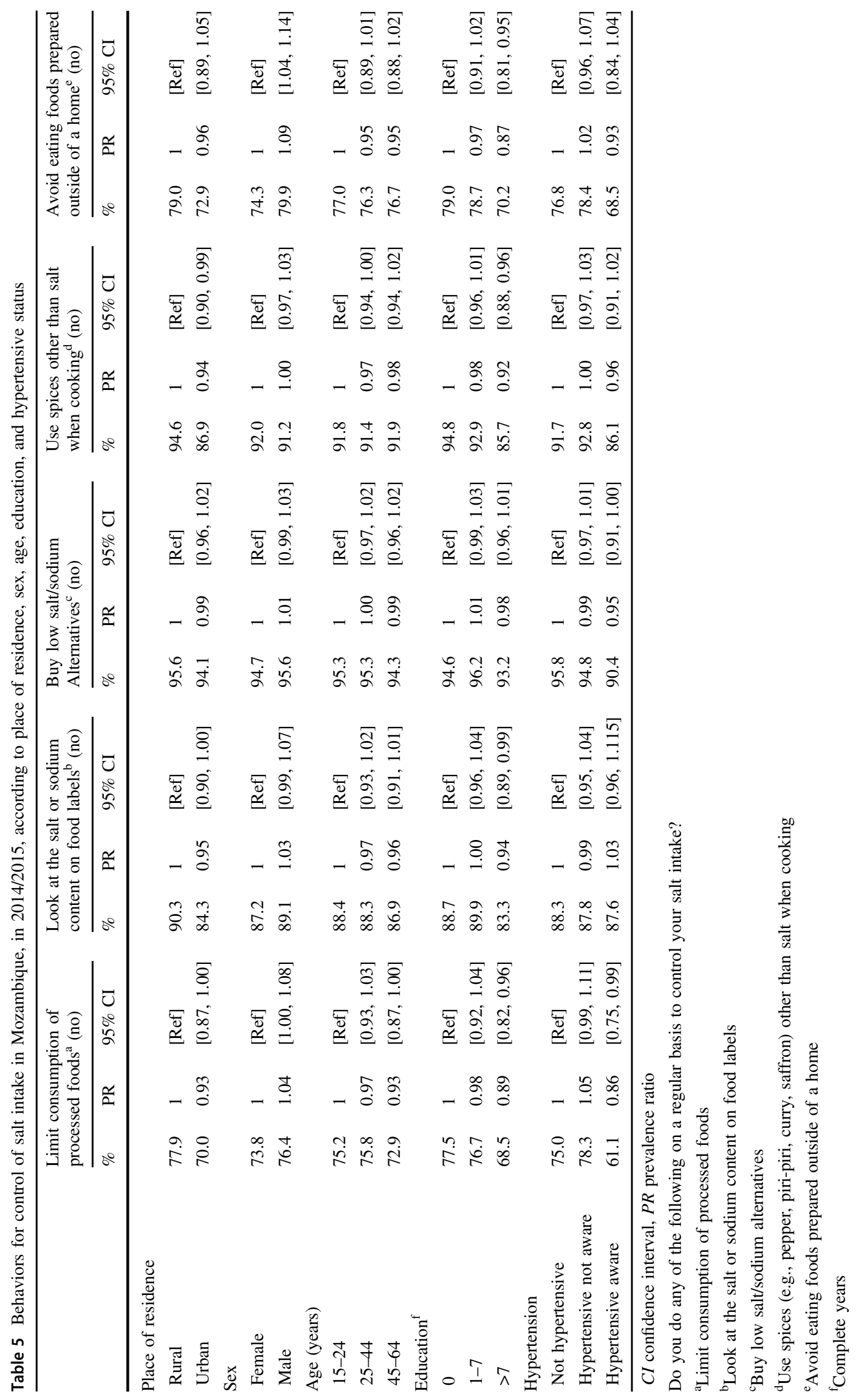


In conclusion, the present study showed that most Mozambicans were aware that high salt intake can cause health problems, but the self-reported salt intake and behaviors for its control show an ample margin for improvement. This study represents an important step in the understanding of patterns of sodium consumption in Mozambique, providing evidence to guide population level effective salt-reduction actions.

\section{Compliance with ethical standards}

Conflict of interest The authors declare that they have no conflict of interest.

\section{References}

1. Brown I, Tzoulaki I, Candeias V, Elliott P. Salt intakes around the world: implications for public health. Int $\mathrm{J}$ Epidemiol. 2009;38:791-813.

2. Powles J, Fahimi S, Micha R, Khatibzadeh S, Shi P, Ezzati M. Global, regional and national sodium intakes in 1990 and 2010: a systematic analysis of $24 \mathrm{~h}$ urinary sodium excretion and dietary surveys worldwide. BMJ Open. 2013;3:e003733.

3. Nagata C, Takatsuka N, Shimizu N, Shimizu H. Sodium intake and risk of death from stroke in Japanese men and women. Stroke. 2004;35:1543-7.

4. Xie JX, Sasaki S, Joossens JV, Kesteloot H. The relationship between urinary cations obtained from the INTERSALT study and cerebrovascular mortality. J Hum Hypertens. 1992;6:17-21.

5. Tsugane S, Sasazuki S, Kobayashi M, Sasaki S. Salt and salted food intake and subsequent risk of gastric cancer among middleaged Japanese men and women. Br J Cancer. 2004;90:128-34.

6. Wang X-Q, Terry PD, Yan H. Review of salt consumption and stomach cancer risk: epidemiological and biological evidence. World J Gastroenterol. 2009;15:2204-13.

7. Martini LA, Cuppari L, Colugnati FA, Sigulem DM, Szejnfeld VL, Schor N, et al. High sodium chloride intake is associated with low bone density in calcium stone-forming patients. Clin Nephrol. 2000;54:85-93.

8. Antonios T, MacGregor G. Salt intake: potential deleterious effects excluding blood pressure. J Hum Hypertens. 1995;9:511-5.

9. World Health Organization (WHO). Guideline: sodium intake for adults and children. http://apps.who.int/iris/bitstream/10665/ 77985/1/9789241504836_eng.pdf?ua $=1 \& u a=1.2012$. Accessed 2 Feb 2017

10. Oyebode O, Oti S, Chen Y-F, Lilford RJ. Salt intakes in subSaharan Africa: a systematic review and meta-regression. Popul Health Metr. 2016;14:1.

11. Queiroz A, Damasceno A, Jessen N, Novela C, Moreira P, Lunet $\mathrm{N}$, et al. Urinary sodium and potassium excretion and dietary sources of sodium in Maputo, Mozambique. Nutrients. 2017;9:830

12. Jessen N, Damasceno A, Silva-Matos C, Tuzine E, Madede T, Mahoque R, et al. Hypertension in Mozambique: trends between 2005 and 2015. J Hypertens. 2017. https://doi.org/10.1097/HJH. 0000000000001618.

13. Instituto Nacional de Estatística. III Recenseamento Geral da População. http://www.ine.gov.mz/operacoes-estatisticas/censos/ censo-2007.2007. Accessed 6 Feb 2017.
14. World Health Organization (WHO). STEPS manual. http://www. who.int/chp/steps/manual/en/. Accessed 6 Feb 2017.

15. World Health Organization (WHO). The STEPS instrument and support materials. http://www.who.int/chp/steps/instrument/en/. Accessed 6 February 2017.

16. Kehoe J. Basic item analysis for multiple-choice tests. Pract Assess Res Eval. 1995;4:20-4.

17. R Core Team. R: a language and environment for statistical computing. Vienna, Austria: R Foundation for Statistical Computing; 2016.

18. Land MA, Webster J, Christoforou A, Johnson C, Trevena H, Hodgins $\mathrm{F}$, et al. The association of knowledge, attitudes and behaviours related to salt with 24-hour urinary sodium excretion. Int J Behav Nutr Phys Act. 2014;11:47.

19. Claro RM, Linders H, Ricardo CZ, Legetic B, Campbell NR. Consumer attitudes, knowledge, and behavior related to salt consumption in sentinel countries of the Americas. Pan Am J Public Health. 2012;32:265-73.

20. Nasreddine L, Akl C, Al-Shaar L, Almedawar MM, Isma'eel H. Consumer knowledge, attitudes and salt-related behavior in the Middle-East: the case of Lebanon. Nutrients. 2014;6:5079-102.

21. Johnson C, Mohan S, Rogers K, Shivashankar R, Thout S, Gupta $\mathrm{P}$, et al. The association of knowledge and behaviours related to salt with 24-h urinary salt excretion in a population from North and South India. Nutrients. 2017;9:144.

22. Sarmugam R, Worsley A. Current levels of salt knowledge: a review of the literature. Nutrients. 2014;6:5534-59.

23. Magalhães P, Sanhangala EJR, Dombele IM, Ulundo HSN, Capingana DP, Silva ABT. Knowledge, attitude and behaviour regarding dietary salt intake among medical students in Angola. Cardiovasc J Afr. 2015;26:57-62.

24. Mushoriwa F, Townsend N, Srinivas S. Knowledge, attitudes and perception on dietary salt reduction of two communities in Grahamstown, South Africa. Nutr Health. 2017;23:33-8.

25. Newson RS, Elmadfa I, Biro G, Cheng Y, Prakash V, Rust P, et al. Barriers for progress in salt reduction in the general population. Int Study Appetite. 2013;71:22-31.

26. Grimes CA, Riddell LJ, Nowson CA. Consumer knowledge and attitudes to salt intake and labelled salt information. Appetite. 2009;53:189-94.

27. Sarmugam R, Worsley A, Wang W. An examination of the mediating role of salt knowledge and beliefs on the relationship between socio-demographic factors and discretionary salt use: a cross-sectional study. Int J Behav Nutr Phys Act. 2013;10:25.

28. Cornelio ME, Gallani MC, Godin G, Rodrigues RC, Nadruz W Jr., Mendez RD. Behavioural determinants of salt consumption among hypertensive individuals. J Human Nutr Diet. 2012;25:334-44.

29. United Nations, Department of Economic and Social Affairs, Population Division. World population prospects: the 2014 revision. http://esa.un.org/wpp/documentation/WPP\%202010\% 20publications.htm. Accessed 11 Feb 2017.

30. Van de Vijver S, Akinyi H, Oti S, Olajide A, Agyemang C, Aboderin I, et al. Status report on hypertension in Africa-consultative review for the 6th Session of the African Union Conference of Ministers of Health on NCD's. Pan Afr Med J. 2013;16:38.

31. Soederberg Miller LM, Cassady DL. The effects of nutrition knowledge on food label use: a review of the literature. Appetite. 2015;92:207-16.

32. Boletim Da República. Decreto 15/2006 de 22 de Junho. Regulamento sobre os Requisitos Higiénico-sanitários de Produção, Transporte, Comercialização e Inspecção e Fiscalização de Géreneros Alimentícios. http://embalagens.gov.mz/docs/ind/embala gens/empresas/fotos/Regulamento\%20sobre\%20requisitos\% 
20Higi\%C3\%A9nico-sanit\%C3\%A1 rios\%20de\%20produ\%C3\% A7\%C3\%A3o.pdf.2006. Accessed 2 January 2017.

33. Sousa S, Damasceno A, Gelormini M, Jessen N, Lunet N, Padrao P. Powdered chicken stock may be an important source of dietary sodium intake in Maputo, Mozambique. J Public Health. 2017:1-2. https://doi.org/10.1093/pubmed/fdx113.

34. Kerry SM, Emmett L, Micah FB, Martin-Peprah R, Antwi S, Phillips RO, et al. Rural and semi-urban differences in salt intake, and its dietary sources, in Ashanti, West Africa. Ethn Dis. 2005;15:33-9.

35. Marakis G, Tsigarida E, Mila S, Panagiotakos DB. Knowledge, attitudes and behaviour of Greek adults towards salt consumption: a Hellenic Food Authority project. Public Health Nutr. 2013;17:1877-93.

36. Zhang J, Wu T, Chu H, Feng X, Shi J, Zhang R, et al. Salt intake belief, knowledge, and behavior: a cross-sectional study of older rural Chinese adults. Medicine. 2016;95:e4404.

37. Baker P, Dworkin S, Tong S, Banks I, Shand T, Yamey G. The men's health gap: men must be included in the global health equity agenda. Bulletin of the World Health Organization. http://www.who.int/bulletin/volumes/92/8/13-132795/en/2014. Accessed 12 March 2017.

38. Our Africa, SOS children. Status of women. http://www.our-a frica.org/women. Accesssed 11 Apr 2017.

39. United Nations University. Overall status of women in Africa. http://archive.unu.edu/unupress/unupbooks/uu37we/uu37we0t. htm. Accessed 11 Apr 2017.

40. Stamler J. The Intersalt Study: background, methods, findings, and implications. Am J Clin Nutr. 1997;65(2 Suppl):626s-42s.
41. Sacks FM, Svetkey LP, Vollmer WM, Appel LJ, Bray GA, Harsha D, et al. Effects on blood pressure of reduced dietary sodium and the dietary approaches to stop hypertension (DASH) diet. N Engl J Med. 2001;344:3-10.

42. He FJ, Li J, MacGregor GA. Effect of longer term modest salt reduction on blood pressure: cochrane systematic review and meta-analysis of randomised trials. BMJ. 2013;346:f1325.

43. Aburto NJ, Ziolkovska A, Hooper L, Elliott P, Cappuccio FP, Meerpohl JJ. Effect of lower sodium intake on health: systematic review and meta-analyses. BMJ. 2013;346:f1326.

44. Cappuccio F, Capewell S. Facts issues and controversies in salt reduction for the prevention of cardiovascular disease. Funct Food Rev. 2015;7:41-61.

45. He FJ, MacGregor GA. A comprehensive review on salt and health and current experience of worldwide salt reduction programmes. J Hum Hypertens. 2009;23:363-84.

46. World Health Organization (WHO). Creating an enabling environment for population-based salt reduction strategies: report of a joint technical meeting held by WHO and the Food Standards Agency, United Kingdom, July 2010. Geneva. Switzerland; 2010. pp. 1-42. http://apps.who.int/iris/handle/10665/44474. Accessed 20 Feb 2017.

47. Wang G, Bowman BA. Recent economic evaluations of interventions to prevent cardiovascular disease by reducing sodium intake. Curr Atheroscler Rep. 2013;15:349.

48. Trieu K, McMahon E, Santos JA, Bauman A, Jolly K-A, Bolam B, et al. Review of behaviour change interventions to reduce population salt intake. Int $\mathrm{J}$ Behav Nutr Phys Act. 2017;14:17. 